\title{
Mapeamento Cartográfico do município de Riachuelo estado de Sergipe
}

\author{
The cartographic mapping of Richuelo town - Sergipe \\ Felippe Pessoa de Melo \\ Governo do Estado de Alagoas \\ Prefeitura Municipal de Garanhuns \\ Universidade Federal de Sergipe
}

\section{Resumo}

O presente trabalho tem como objetivo confeccionar a base cartográfica do Município de Riachuelo Estado de Sergipe, para isso foram utilizadas as tecnologias do Sensoriamento Remoto e Sistema de Informações Geográficas-SIG, as quais possibilitaram a confecção de um banco de dados geográficos com informações matriciais e vetoriais. Tornando possível realizar as correlações entre os distintos modelos de dados em um mesmo ambiente virtual, o que maximiza a qualidade dos produtos oriundos dessas inter-relações. Dessa forma foram confeccionadas as cartas temáticas referentes aos seus aspectos físicos. De posse desse material o Município de Riachuelo passou a ter materiais cartográficos que facilitaram a tomada de decisões para implementação de políticas públicas que estejam em consonância com o desenvolvimento sustentável.

Palavras-chaves: : Geotecnologias, mapas temáticos e desenvolvimento sustentável.

\begin{abstract}
The present work aims to fabricate the base map of the City of Brook State of Sergipe, for this, we used the technologies of Remote Sensing and Geographic Information System-GIS, which enabled the manufacturing of a geographic database with information matrix and vector. Making it possible to perform the correlations between different data models on the same virtual environment, which maximizes the quality of the products from these interrelationships. Thus, the thematic maps were made relating to its physical aspects. Possession of such material the municipality of Riachuelo started having cartographic materials that facilitated decision making for implementation of public policies that are consistent with sustainable development.
\end{abstract}

Keywords: geotechnology, thematic maps and sustainable development. 


\section{INTRODUÇÃO}

"O Estado de Sergipe está localizado na região Nordeste do Brasil e abrange uma superfície de cerca de $22.000 \mathrm{~km}^{2}$, sendo parcialmente incluído no denominado Polígono das Secas, que apresenta um regime pluviométrico marcado por extrema irregularidade de chuvas, no tempo e no espaço. Nesse cenário, a escassez de água constitui um forte entrave ao desenvolvimento socioeconômico e, até mesmo, à subsistência da população. A ocorrência cíclica das secas e seus efeitos catastróficos são por demais conhecidos e remontam aos primórdios da história do Brasil." (BOMFIM, et al. 2002).

Estando a província de Riachuelo situada na porção centro-oeste de Sergipe.

O Município de Riachuelo não possui uma base de dados cartográficos própria, para suprir essa carência são utilizadas cartas temáticas do Instituto Brasileiro de Geografia e EstatísticaIBGE, mas as escalas utilizadas pelo IBGE não possibilitam analisar de maneira mais detalhada as características geográficas da área em questão, o mapa que representa as características físicas de Sergipe está na escala de 1:1.800.000, o que impossibilita utilizar essas informações para ações relacionadas à implantação de planos gestores, simulações de enchentes, planejamentos urbanos e administração de recursos minerais.

"A coleta de informações sobre a distribuição geográfica de recursos minerais, propriedades, animais e plantas sempre foi uma parte importante das atividades das sociedades organizadas. Até recentemente, no entanto, isto era feito apenas em documentos e mapas em papel, isto impedia uma análise que combinasse diversos mapas e dados. Com o desenvolvimento simultâneo, na segunda metade do século passado da tecnologia de informática, tornou-se possível armazenar e representar tais informações em ambiente computacional, abrindo espaço para o aparecimento do Geoprocessamento. É uma tecnologia interdisciplinar, que permite a convergência de diferentes disciplinas científicas para o estudo de fenômenos ambientais e urbanos. Ou ainda, que "o espaço é uma linguagem comum" para as diferentes disciplinas do conhecimento. $\mathrm{O}$ que facilita a compilação e interpretação dos dados obtidos pelo SIG. Do ponto de vista da tecnologia, desenvolver um SIG significa oferecer o conjunto mais amplo possível de estruturas de dados e algoritmos capazes de representar a grande diversidade de concepções do espaço." (CÂMARA, et al. 2001).

Para subsidiar a carência cartográfica, foram utilizadas as tecnologias do Sensoriamento Remoto e SIG, esses recursos possibilitaram a confecção de um banco de dados geográficos, com informações matriciais e vetoriais. O que permitiu realizar correlações entre essas distintas formas de dados e possibilitou a confecção das cartas temáticas de Riachuelo, referentes aos seus aspectos geográficos. Facilitando a implantação de medidas para recuperação de áreas degradadas e maximizando a qualidade de vida da população local.

Para Afonso (2002), SIG é uma coleção organizada de hardware, software, dados geográficos e pessoal envolvido no trabalho, projetado para capturar, armazenar, atualizar, manipular, analisar e apresentar todas as formas de informações referenciadas geograficamente.

Nessa perspectiva o presente trabalho fica em consonância com os procedimentos metodológicos propostos por Libault (1971).

"A pesquisa de caráter geográfico deve ocorrer nos níveis: compilatório, correlatório, semântico e normativo. No primeiro nível ocorre o levantamento bibliográfico e cartográfico, escolha do local da pesquisa e da escala de estudo adequada. No segundo serão realizadas as inter-relações entre os elementos responsáveis pela dinâmica superficial, a partir da escolha de indicadores ambientais para avaliar o grau de instabilidade. O terceiro é responsável pela síntese, onde são nomeadas as normas de inter-relações entres as diversas variáveis. No último nível é realizada a confecção do mapa morfodinâmico." (LIBAULT, 1971).

\section{LOCALIZAÇÃO DA ÁREA}

O Município está localizado na Região Nordeste do Brasil, no Estado de Sergipe. Faz divisa com as cidades de: Malhador, Santa Rosa de Lima, Divina Pastora, Laranjeiras e Areia Branca (Figura 1). Está a 29,7 km de Aracaju, capital sergipana. 


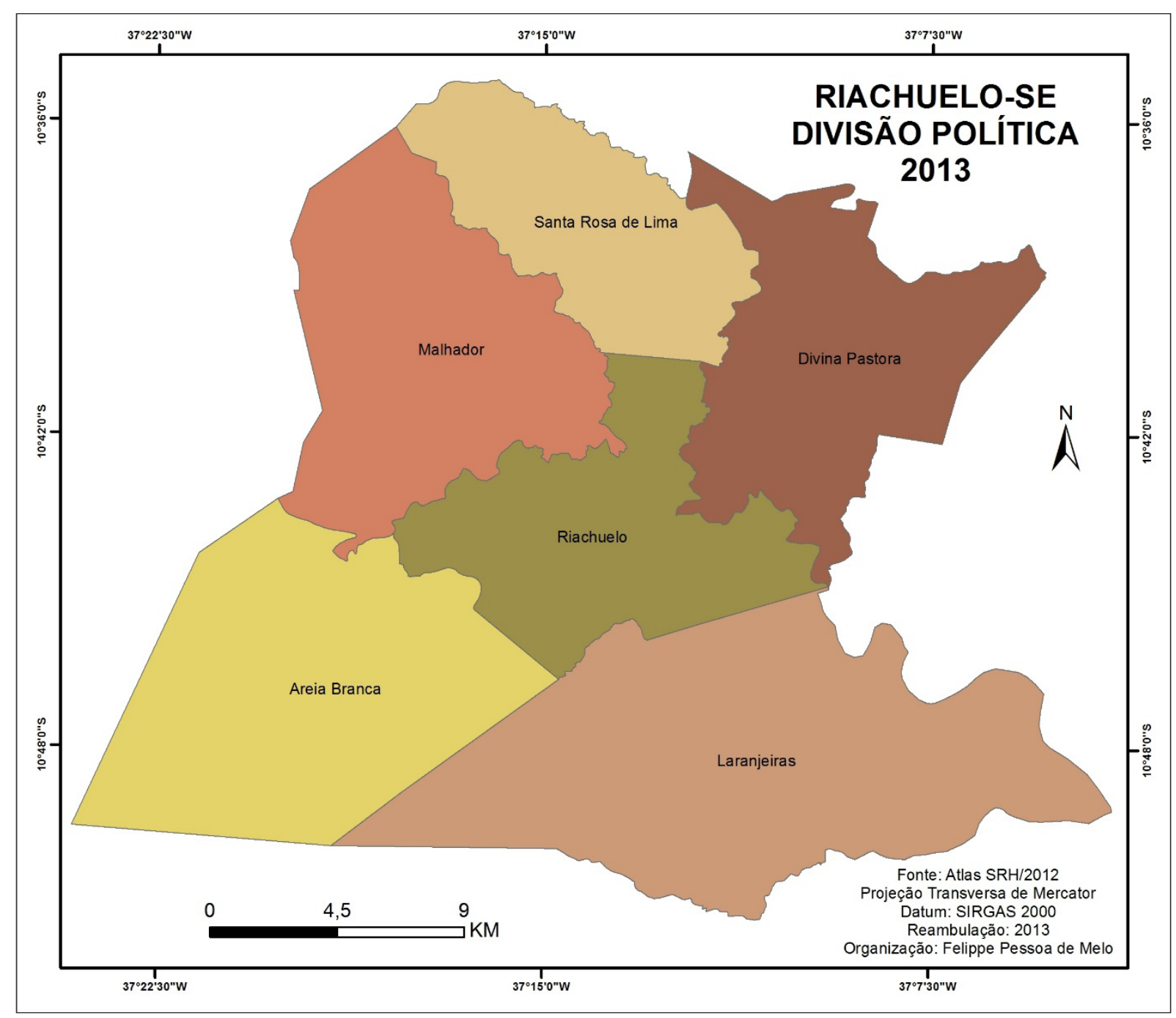

Figura 1. Localização da área de estudo na escala de 1:450.000. Fonte: Atlas SRH/2012.

\section{METODOLOGIA}

Realizou-se uma pesquisa de gabinete, com a finalidade de conhecer o material bibliográfico referente à temática e baixar os dados vetoriais e matriciais correspondentes ao perímetro do local de estudo.

Logo em seguida confeccionou-se um banco de dados geográficos georreferenciados no Sistema de Informações Geográficas ArcGIS 10.1 (2010).

De posse dos dados em um ambiente virtual foram feitas as correlações entre as informações, o que possibilitou a confecção de cartas temáticas necessárias, com escalas entre $1 \mathrm{~km}$ e $4,5 \mathrm{~km}$.

Posteriormente realizou-se a pesquisa de campo objetivando confirmar as informações obtidas em gabinete, editar e reambular quando necessário. Após essa etapa as cartas temáticas foram reimpressas e reanalisadas. Tornando os resultados oriundos das correlações entre dados virtuais e de campo, mais fidedignos a realidade.
Na confecção do mapa hipsométrico foram estabelecidas seis classes com cotas altimétricas de $40 \mathrm{~m}$.

\section{RESULTADOS E DISCUSSÕES}

O Município de Riachuelo está localizado sob o domínio das Províncias São Francisco do Norte e Borborema (Figura 2). A segunda apresenta maior representatividade, $649,61 \mathrm{~km}^{2}$, o que equivale a $78,67 \%$ do território municipal.

Sua topografia apresenta cotas altimétricas com altitudes modestas, elas oscilam de 0 a 200m (Figura 3). Entretanto no perímetro urbano as cotas altimétricas são de $30 \mathrm{~m}$ (BOMFIM, et al. 2002). Aplicando o modelo de classificação taxonômica do relevo proposto por Ross (1992), foram encontradas cinco Unidades Morfológicas ou Padrões de Formas (Figura 3).

As unidades com cotas ente 0 e $40 \mathrm{~m}$ se sobressaem diante das demais devido sua grande 


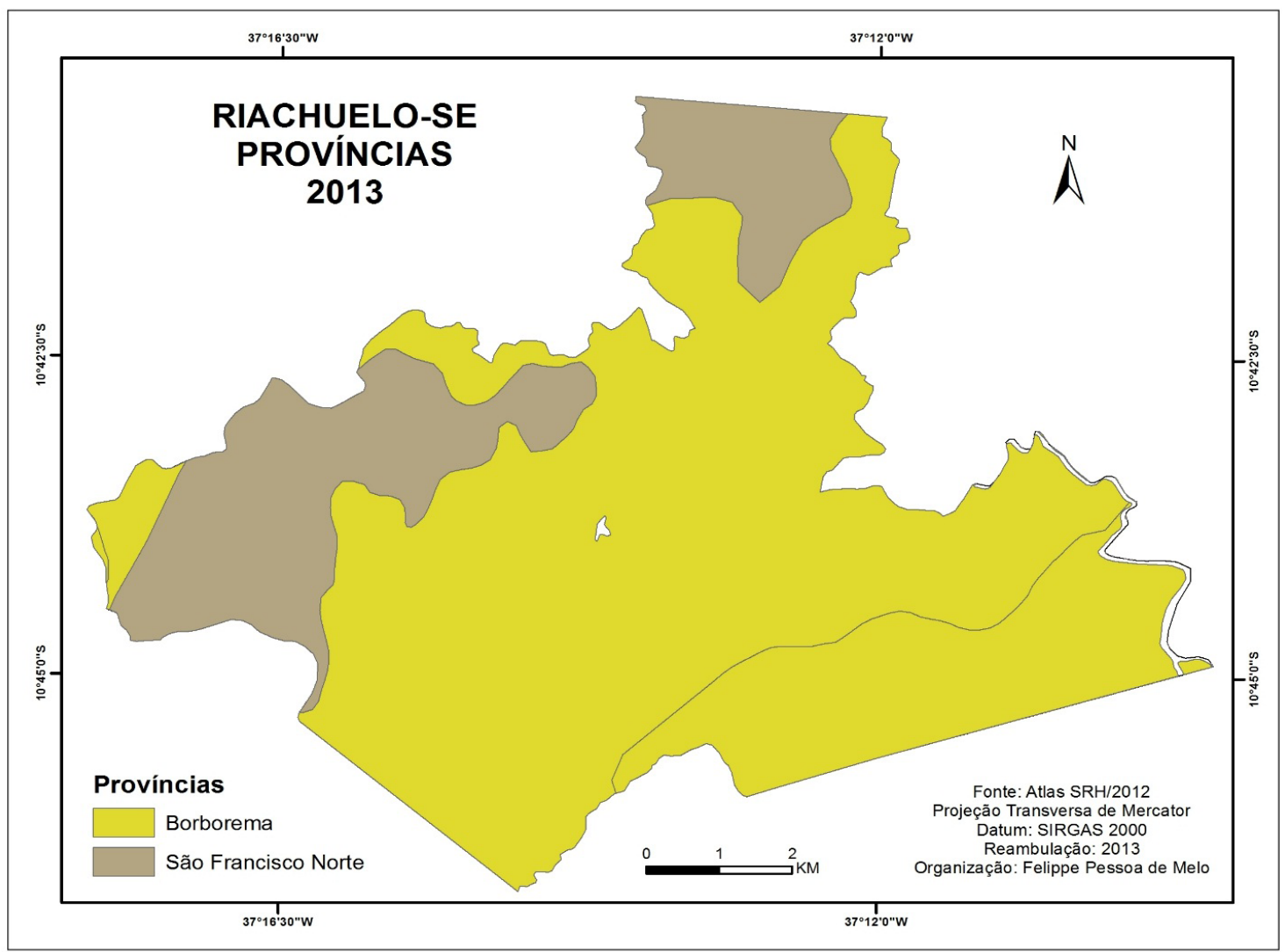

Figura 2. Distribuição territorial das províncias na escala de 1:100.000. Fonte: Atlas SRH/2012.

representatividade no perímetro urbano (Tabela 1). com maior representatividade (Tabela 2). Essas for-

De acordo com a CPRM (2006), geologi- mações são bem diversificadas em termos litológicos camente a área está inserida em cinco formações (Figura 5). distintas (Figura 4), destacando-se a Unidade Angico, Observando-se as Figuras 4 e 5 e Tabela 2 nota-se

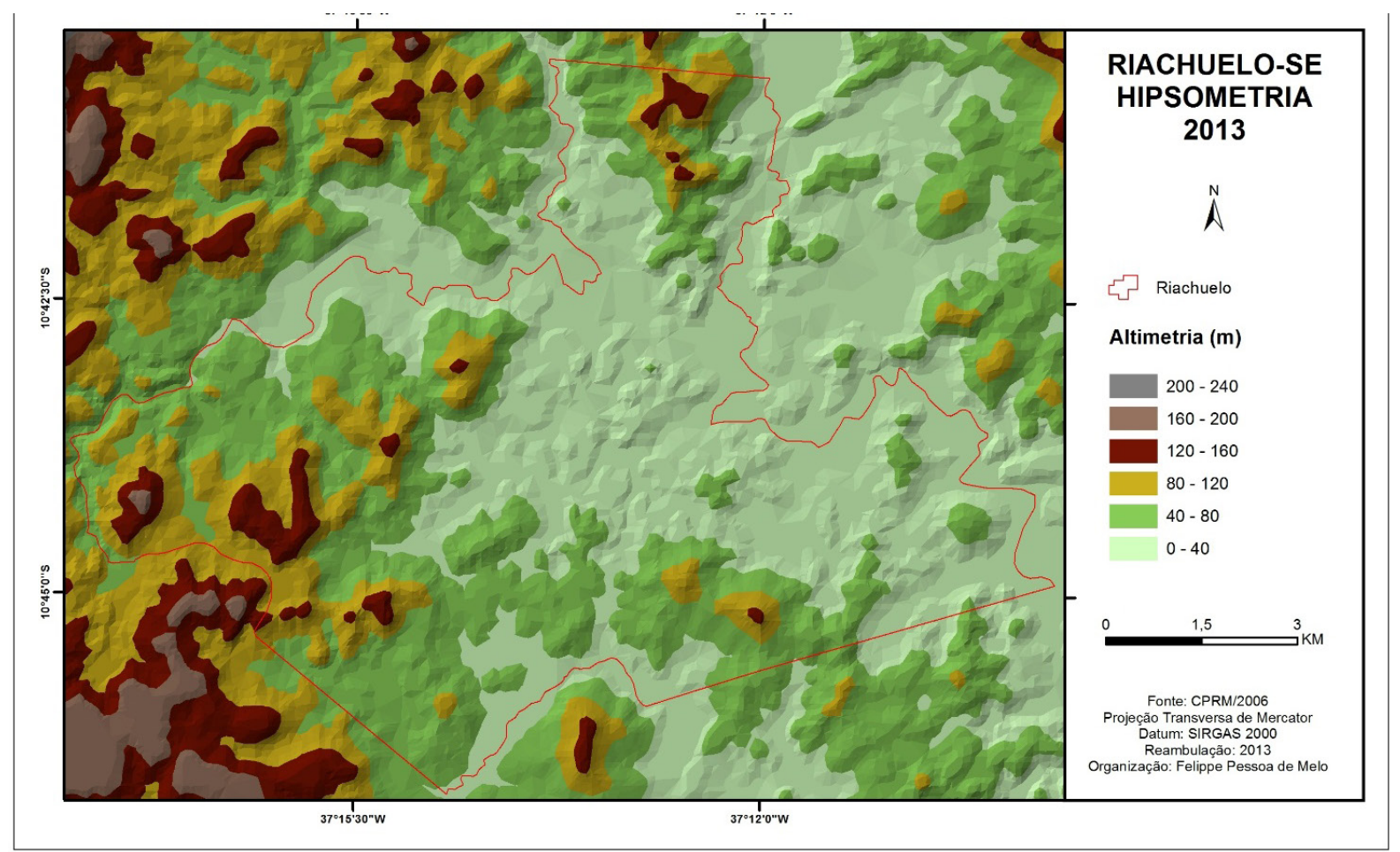

Figura 3. Altimetria do modelado na escala de 1:150.000. Fonte: CPRM/2006. 
Tabela 1. Subdivisões do modelado.

\begin{tabular}{|c|c|c|c|c|c|}
\hline Altimetria (m) & Área $\left(\mathrm{Km}^{2}\right)$ & Percentual (\%) & Altimetria (m) & Área $\left(\mathrm{Km}^{2}\right)$ & Percentual (\%) \\
\hline $160-200$ & 1,08 & 0,13 & $40-80$ & 253 & 30,64 \\
\hline $120-160$ & 21,2 & 2,56 & $0-40$ & 457,42 & 55,39 \\
\hline $80-120$ & 93 & 11,26 & \multicolumn{3}{|c|}{ 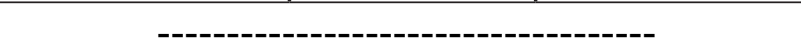 } \\
\hline \multicolumn{2}{|c|}{ Área Total $\left(\mathrm{Km}^{2}\right)$} & \multicolumn{4}{|c|}{825,70} \\
\hline
\end{tabular}

Fonte: CPRM/2006.

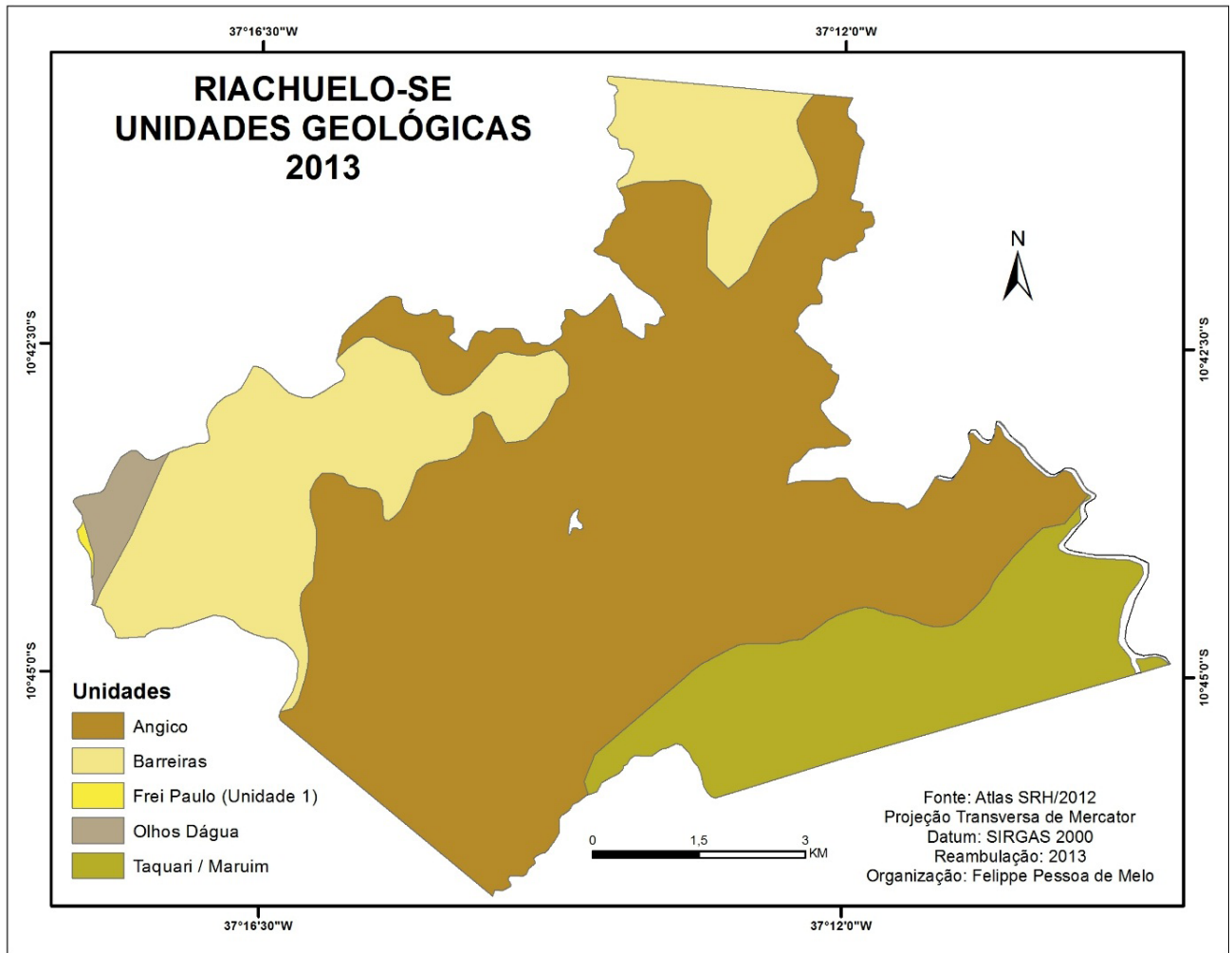

Figura 4. Unidades aflorantes na escala de 1:150.000. Fonte: Atlas SRH/2012.

Tabela 2. Unidades aflorantes na área de estudo.

\begin{tabular}{c|c|c}
\hline Unidades Geológicas & Área $\left(\mathrm{Km}^{2}\right)$ & Percentual $(\%)$ \\
\hline Angico & 506,82 & 61,38 \\
\hline Barreiras & 175,94 & 21,30 \\
\hline Frei Paulo (Unidade 1) & 0,59 & 0,07 \\
\hline Olhos Dágua & 11,27 & 1,36 \\
\hline Taquari / Maruim & 131,08 & 15,87 \\
\hline Área Total $\left(\mathrm{Km}^{2}\right)$ & 825,70 & \\
\hline
\end{tabular}




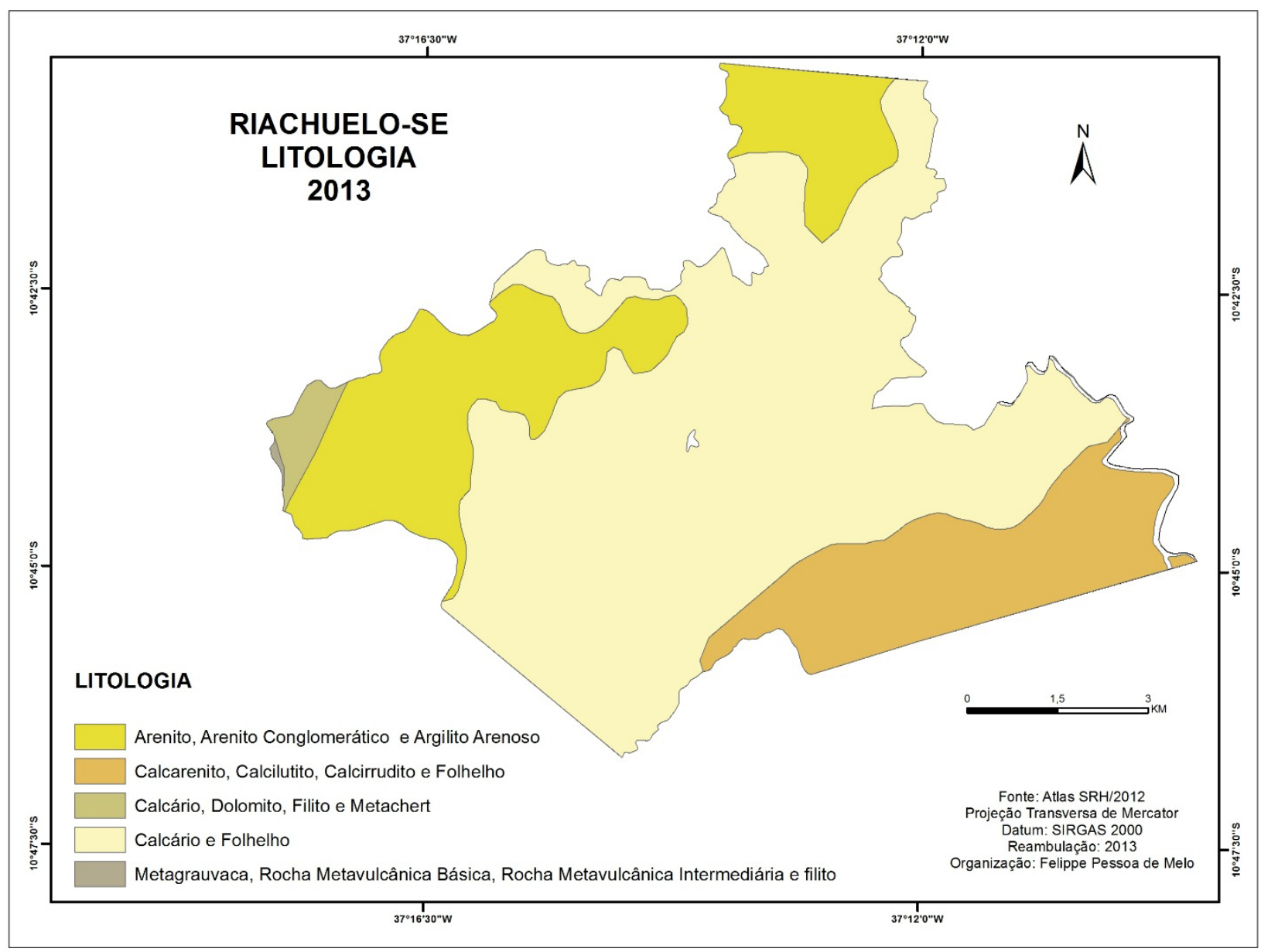

Figura 5. Características litológicas na escala de 1:1500.000.. Fonte: Atlas SRH/2012.

a ampla predominância da Unidade Angico, sendo formada por: calcário e folhelho. Em relação a Unidade Barreiras ela é rica em: arenito, arenito conglomerático e argilito arenoso. Já a Unidade Taquari/Maruim possui a presença de: calcarenito, caucilutito, caucirrudito e folhelho. A Unidade Olhos D'água e composta por: calcário, dolomito, filito e metachert. A Unidade Frei Paulo (1) é constituída de: metagrauvaca, rocha metavulcânica básica, rocha metavulcânica intermediária e filito.

Geomorfologicamente suas unidades estão distribuídas de maneira desuniforme (Tabela 3), o intenso trabalho da drenagem fica evidenciado com o grande destaque que a unidade denominada de Superfície dos Rios ocupa na paisagem (Figura 6).

O Município apresenta seis tipos distintos de solos (Tabela 4), distribuídos de maneira bem variada ao longo do perímetro municipal, com ampla predominância de solos Podzólico vermelho-amarelo oriundo, principalmente, das unidades Angico e Barreiras (Figura 7). Apresenta uma rica rede hidrográfica (Figura 8), as quais pertencem as Bacias: Atlântico Sul-Leste e Sub-bacia Hidrográfica Vaza-Barris, Itapicuru e outras.

Tabela 3. Distribuição das unidades geomorfológicas.

\begin{tabular}{c|c|c}
\hline Unidades Geomorfológicas & Área $\left(\mathrm{Km}^{2}\right)$ & Percentual (\%) \\
\hline Planície Costeira & 110,82 & 13,42 \\
\hline Serras Residuais & 84,51 & 10,23 \\
\hline Superfície dos Rios & 630,37 & 76,34 \\
\hline Área Total $\left(\mathrm{Km}^{2}\right)$ & 825,70 & \\
\hline
\end{tabular}

Fonte: Atlas SRH/2012. 


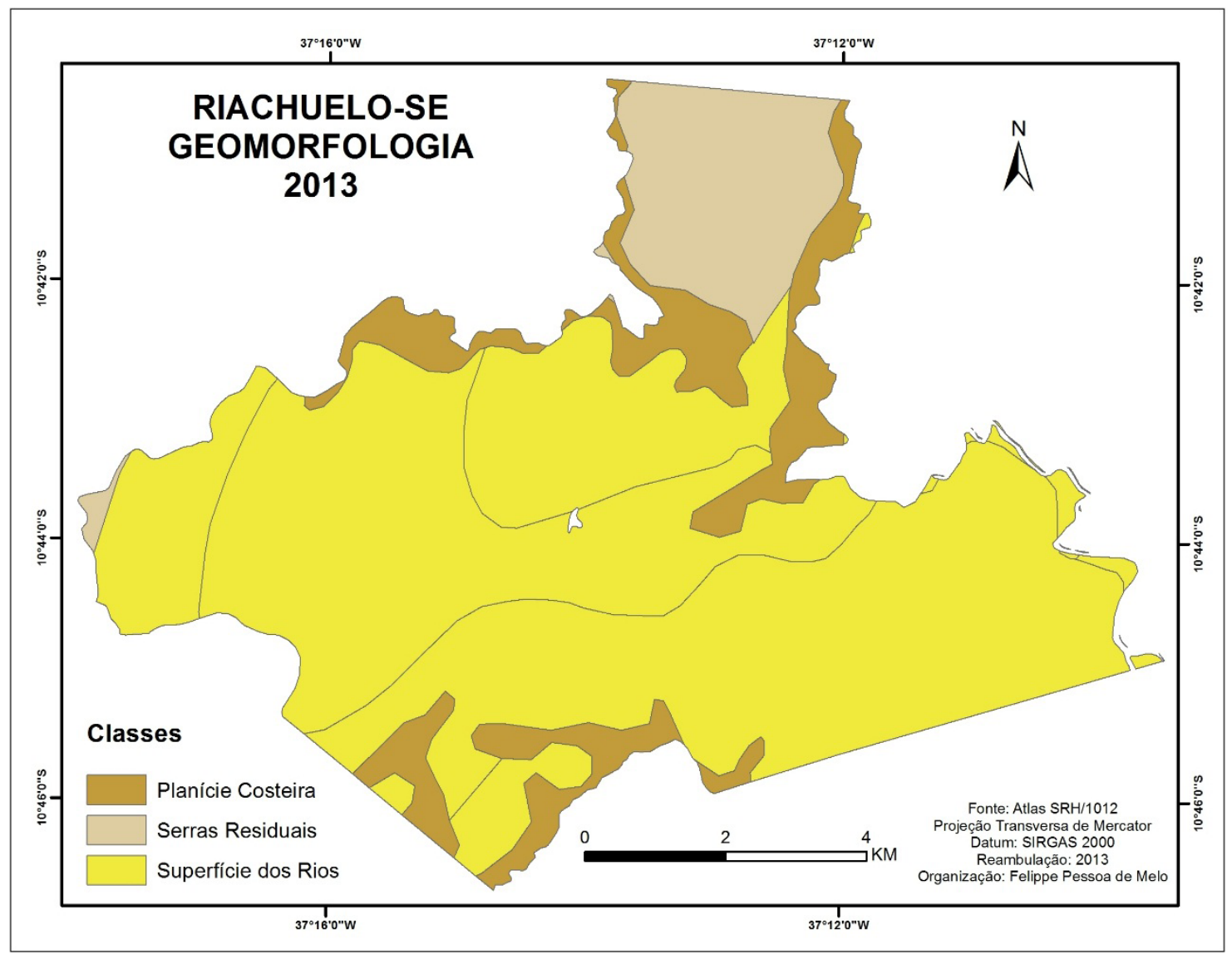

Figura 6. Unidades morfoesculturais na escala de 1:200.000. Fonte: Atlas SRH/2012.

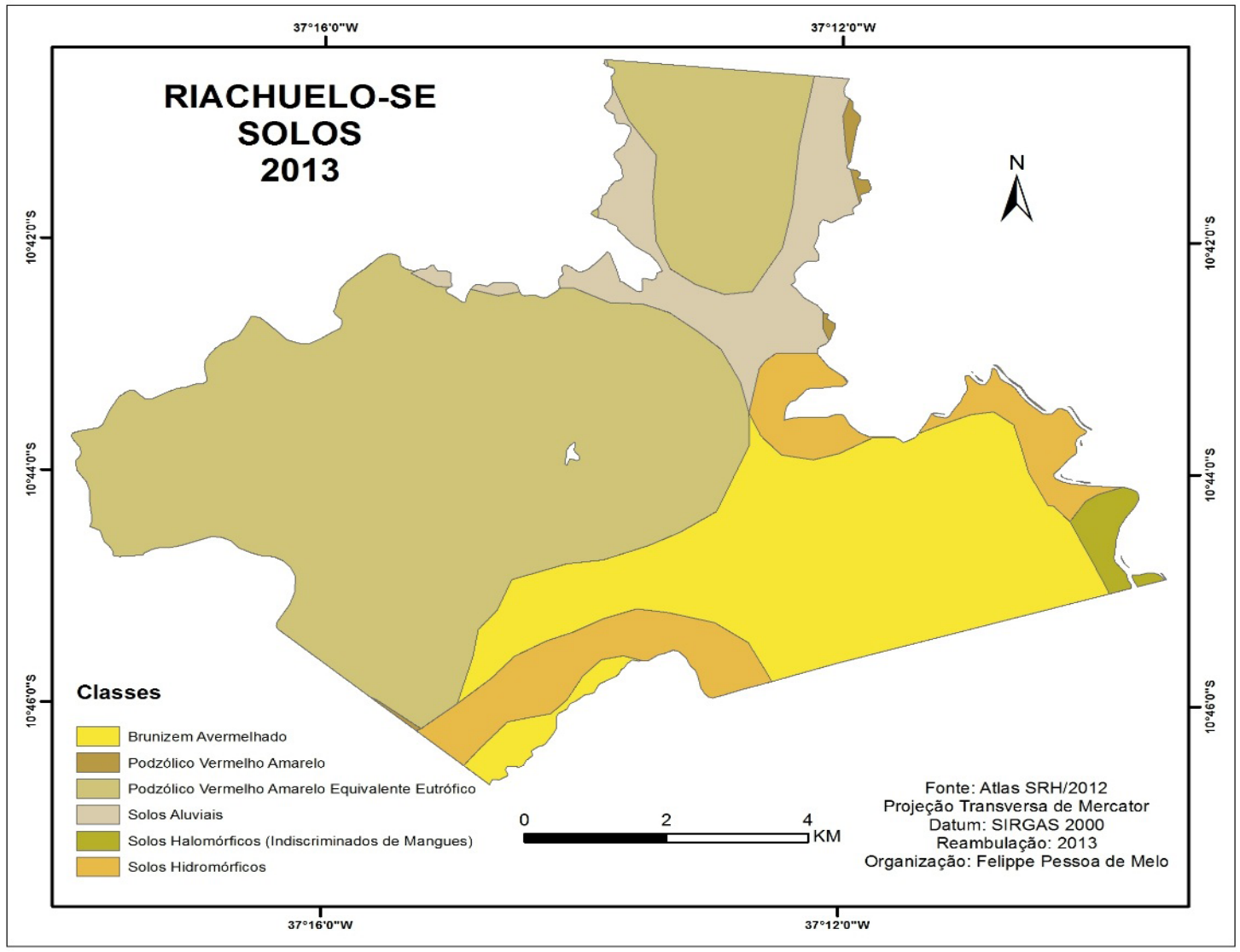

Figura 7. Distribuição dos solos na escala de 1:200.000. Fonte: Atlas SRH/2012. 


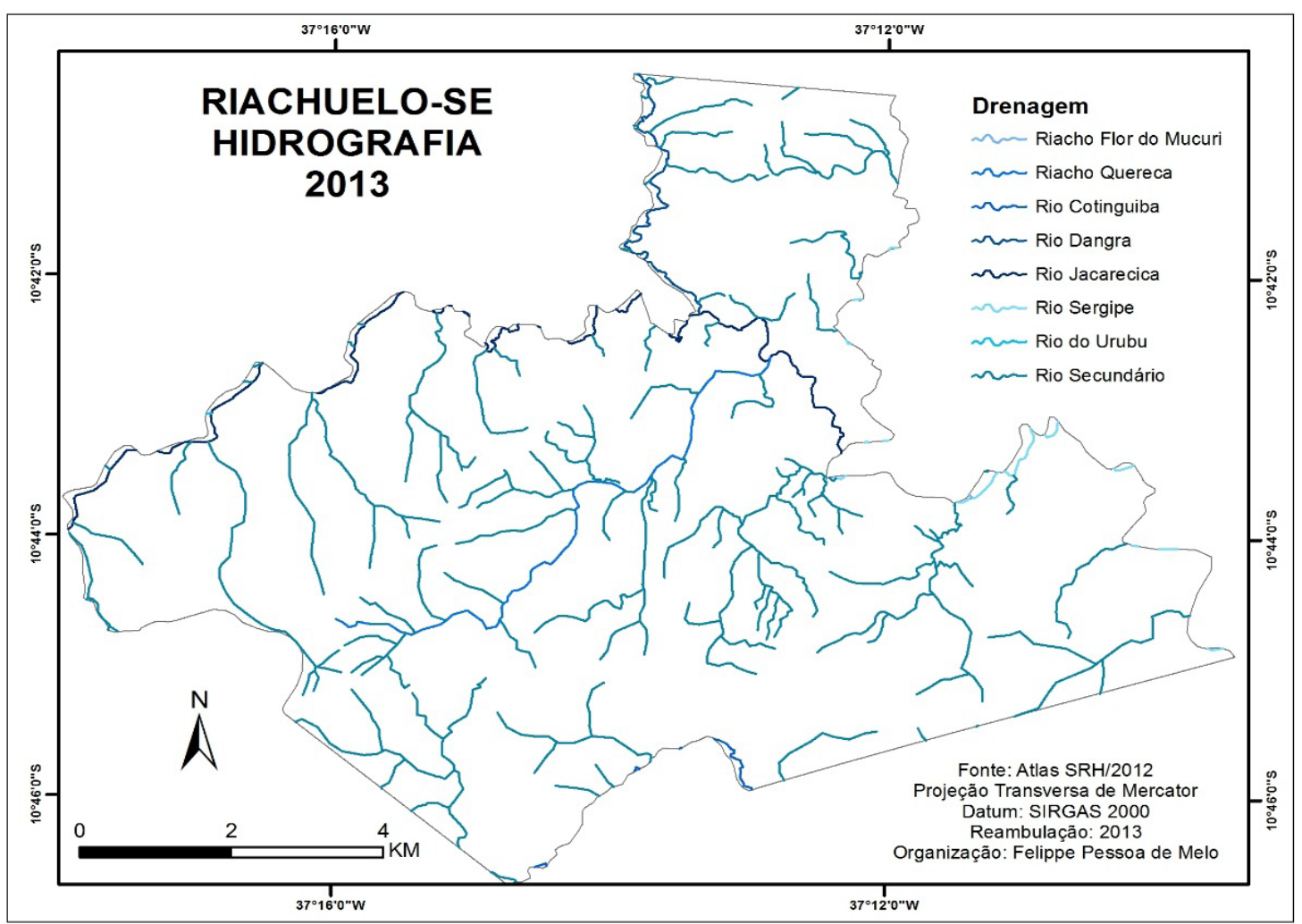

Figura 8. Rede hidrográfica na escala de 1:200.000. Fonte: Atlas SRH/2012.

Tabela 4. Distribuição dos solos.

\begin{tabular}{c|c|c}
\hline Solos & Área $\left(\mathrm{Km}^{2}\right)$ & Percentual (\%) \\
\hline Brunizem Avermelhado & 263,31 & 31,88 \\
\hline Podzólico Vermelho Amarelo & 2,77 & 0,33 \\
\hline $\begin{array}{c}\text { Podzólico Vermelho Amarelo } \\
\text { Equivalente Eutrófico }\end{array}$ & 465,42 & 56,36 \\
\hline Solos Aluviais & & \\
\hline Solos Halomórficos (Indiscriminados de & & \\
Mangues) & 9,32 & 1,12 \\
\hline Solos Hidromórficos & & 2,67 \\
\hline Área Total (Km $\left.{ }^{2}\right)$ & 825,70 & \\
\hline
\end{tabular}




\section{CONCLUSÕES}

Utilizando as geotecnologias do Sensoriamento Remoto e SIG, foi possível confeccionar um banco de dados geográficos georreferenciados no programa ArcGIS10.1, o qual possibilitou correlacionar informações matriciais e vetoriais de forma ágil e fidedigna a realidade materializada no Município de Riachuelo no Nordeste do Brasil.

De posse dessas informações confeccionouse as cartas temáticas da área de estudo em uma escala que possibilita análises do espaço geográfico mais confiáveis, devido à ampliação do grau de detalhes nas novas cartas. Já que as cartas disponíveis estavam na escala de 1:1.800.000.

Os atuais produtos, disponíveis em escala de maior detalhe, 1:450.000 para divisão política; 1:100.000 em relação as províncias, 1:150.000 para a hipsometria, litologia e geologia e 1:200.000 as cartas que representam a geomorfologia, os solos e a drenagem.

Portanto o geoprocessamento obteve um resultado satisfatório, no que diz respeito a sua aplicabilidade para minimizar problemas relacionados à representatividade do espaço geográfico no Município de Riachuelo.

\section{REFERÊNCIAS BIBLIOGRÁFICAS}

AFONSO, A. 2002. Introdução ao Geoprocessamento e ao Sensoriamento Remoto. Estágio da Docência, Programa de Pós-Graduação do INPE, Universidade Federal de Taubaté, 52 pp.

ArcGIS (v. 10.1) [software]. (2010). Retirado do: $<w w w$.esriportugal.pt $>$.

CÂMARA G.; DAVIS C.; MONTEIRO A. M. V. 2001. Introdução á Ciência da Geoinformação. São José dos Campos. Instituto Nacional de Pesquisas Espaciais, 345pp.

BOMFIM, L. F. C.; Costa, I. V. G. da; Benvenuti, S. M. P. Projeto cadastro da infra-estrutura hídrica do Nordeste: Estado de Sergipe. Riachuelo: CPRM, 2002. <http://www.cprm.gov.br/arquivos/pdf/ dehid/Sergipe/Riachuelo.pdf $>$ Acesso em: 24 de ago. 2013.

CPRM-Companhia de Pesquisa de Recursos Minerais. 2006. Geobank. Disponível em: <http://www. cprm.gov.br/>. Acesso em: 08 de jan. 2013.
IBGE-Instituto Brasileiro de Geografia e Estatística. Banco de Dados. Disponível em: <http://www.ibge. gov.br/home/default.php>. Acesso em 01 de ago. 2013.

LIBAULT, A. 1971. Os quatro níveis de pesquisa geográfica. Métodos em Questão. 1a Ed. São Paulo/ SP.

ROSS, J. L. S. 1992. O Registro Cartográfico dos Fatos Geomórficos e a Questão da Taxonomia do Relevo. São Paulo. Revista do Departamento de Geografia. 6: 17-29.

SILVA, V. de P. R. On climate variability in Northeast of Brazil. Journal of Arid Environments, v.58, n. 4 , p.575-596, 2004.

SRH - Superintendência de Recursos Hídricos. Atlas Digital. Disponível em: < http://www.semarh.se.gov. br/srh/ > Acesso em: 25 de jan. 2013. 